\title{
A Construção Social da Pessoa e a Psiquiatria: Do Alienismo à "Nova Psiquiatria"*
}

ANA TERESA A. VENANCIO**

\section{Apresentação}

A psiquiatria, enquanto saber e prática emergente a partir do século XIX, tem se ocupado da apreensão, enunciação e solução das "perturbações físico-morais" que acometem o ser humano. Entre as teorias e representações pertinentes ao saber e à prática psiquiátrica, algumas privilegiam as causas, aspectos e conseqüências de ordem físico-orgânica; outras dão preeminência às explicações de ordem moral. Essa dualidade físico-moral traduz, mais do que a disputa entre dois modos de compreensão das "perturbações", a tensão constitutiva que caracteriza a construção social da Pessoa moderna em suas diferentes formas de atualização.

Não se trata aqui de reconstituir toda a história da psiquiatria, certamente já escrita, reescrita e passivel de ser contada sob diversos ângulos.

* Este artigo é parte de minha Tese de Mestrado Sobre a "Nova Psiquiatria" no Brasil: Um Estudo de Caso do Hospital-Dia do Instituto de Psiquiatria, apresentada ao Programa de Pós-Graduação em Antropologia Social/Museu Nacional/UFRJ, 1990.

** Socióloga, Mestre em Antropologia Social. 
Neste artigo, tal história é recortada de modo a analisar, primeiramente, a tensão físico-moral constitutiva da noção de Pessoa moderna individualizada, expressa de forma paradigmática por meio da emergência da psiquiatria e de algumas de suas formulações e práticas. Em segundo lugar, este texto focaliza pontos fundamentais das explicações e das técnicas que centram sua atenção na dimensão moral do indivíduo doente, destacando o modo como o ideário característico da primeira psiquiatria, alienista, reaparece de modo particular na "nova psiquiatria". 1

\section{A noção de pessoa ocidental-moderna e o surgimento da psiquiatria}

A noção de Pessoa tem sido objeto de diversas análises antropológicas. O primeiro trabalho nessa linha já indicava que pode haver diferentes sentidos para a vida dos homens em sociedade, segundo seus direitos, religiões, costumes, estruturas sociais e mentalidades, ressaltando-se ainda o quanto é recente a categoria do "eu". ${ }^{2}$ A partir desse estudo, intensifica-se o interesse pela representação de Pessoa que toma forma nas sociedades ocidentais-modernas: o Indivíduo, armado sobre os valores da igualdade e da liberdade. ${ }^{3}$

1 Entendo por "nova psiquiatria" o conjunto de saberes e práticas psiquiátricas levado a efeito no contexto internacional, a partir da Segunda Guerra Mundial, e que vem se contrapondo a um modelo dito "tradicional" pela prevalência da idéia de saúde mental, em detrimento da de doença mental, e pela assunção de uma etiologia ao mesmo tempo individual e social a esse respeito. A locução "nova psiquiatria" é uma expressão do próprio campo psiquiátrico, datada, que aparece em J. Birman e J. F. Costa, "Organização de Instituições para uma Psiquiatria Comunitária", Relatórios e Resumos do $2^{\circ}$ Congresso Brasileiro de Psicopatologia Infanto-Juvenil, Rio de Janeiro, APPIA, 1976; e em F. Basaglia, A Psiquiatria Alternativa: Contra o Pessimismo da Razão o Otimismo da Prática, São Paulo, Ed. Debates, 1979. Minha opção pelo uso de aspas visa tanto relativizar as conotações positivas ou negativas que a expressão possa ter, quanto ressaltar a particular imprecisão e o dinamismo com que o adjetivo "novo" é utilizado em nossa cultura. Neste sentido, é notável que, atualmente, a chamada psiquiatria biológica, oposta ao ideário que denominei de "nova psiquiatria", também se autocaracterize como tal, em conseqüência das "inovações" teóricas e práticas que estaria trazendo para o campo psiquiátrico.

2 Cf. M. Mauss, M. "Uma Categoria do Espírito Humano: A Noção de Pessoa, a Noção do 'Eu'”, Sociologia e Antropologia, vol. 1, São Paulo, EDUSP, 1974, pp. 207-41.

3 Cf. L. Dumont, O Individualismo - Uma Perspectiva Antropológica da Ideologia Moderna, Rio de Janeiro, Ed. Rocco, 1985. Como Louis Dumont, estarei diferenciando o indivíduo enquanto sujeito empírico, isto é, a amostra individual da espécie humana tal como a encontramos em toda e qualquer sociedade, e o sujeito moral, "ser moral independente, autônomo e, por conseguinte, essencialmente não-social” (idem, p. 37). Para a elucidação dessa distinção usarei 
A construção social da idéia de Indivíduo pode ser remetida aos primórdios cristãos, quando o homem passou a ser visto como um "indivíduo-emrelação-com-Deus". A relação filial com Deus, ao mesmo tempo que exacerbava um desvalor do mundo existente, concedia, pela primeira vez, um valor infinito à representação de uma alma individual, igual e universal. No entanto, observa-se que foi somente quando o indivíduo se constituiu como "indivíduo-no-mundo" que ele passou a compor a forma de moderno. Uma qualificação que apareceu em toda a sua plenitude quando, diferentemente de todas as outras sociedades, o mundo ocidental passou a dissociar o poder espiritual do poder temporal, representando-os não mais como divergentes em natureza, mas como poderes de um mesmo nível. Com a separação da Igreja e do Estado e o desenvolvimento do "político" e do "econômico" intensificou-se a conformação do valor-Indivíduo: todo homem sendo, cada vez mais, relacionado ao mundo social e visto como uma unidade em si, concomitantemente igual e diferente de seus pares. ${ }^{4}$

Nesse processo, a própria sociedade veio a significar uma associação de indivíduos que, já totalmente constituídos, nela entrariam voluntariamente, mediante uma espécie de "contrato". Em oposição à universitas — um modelo de sociedade derivado do princípio da hierarquia, que concebe os seres humanos como socialmente determinados e inseridos em um sistema de ordenação do mundo que é tanto "social" quanto "cosmológico" conformava-se o modelo de societas, isto é, um agrupamento de indivíduos moralmente autônomos. ${ }^{5} \mathrm{O}$ sujeito, desatrelado de qualquer transcendência, igual e livre, passou a ser oposto a todos os "determinismos" prescritos pela cultura e/ou sociedade.

Seguindo a argumentação acima e com base em outros autores, que, a partir de diferentes temáticas, vêm tratando da especificidade da sociedade moderna e da idéia de Pessoa que nela se organiza, verifica-se um certo consenso sobre a consolidação da representação social de Indivíduo, e seus corolários, em torno do século XVIII. ${ }^{6}$ Neste período, contribuíram para a

a forma indivíduo quando da acepção de seu primeiro significado e Indivíduo ou Valor-Indivíduo para o segundo sentido.

4 L. Dumont, O Individualismo..., op. cit.; L. Dumont, Homo Hierarchicus, Paris, Gallimard, 1966.

5 Cf. L. Dumont, "The Modern Conception of the Individual Notes on its Genesis and of Concomitant Institutions", Contributions to Indian Sociology, vol. VIII, 1965, pp. 13-61.

6 Cf. P. Ariès, História Social da Criança e da Família, Rio de Janeiro, Zahar Eds., 1978; M. Foucault, História da Sexualidade I: A Vontade de Saber (10 ${ }^{\mathrm{a}}$ ed.), Rio de Janeiro, Ed. Graal, 1988; A. O. Hirschman, As Paixões e os Interesses, Rio de Janeiro, Paz e Terra, 1979; C.B. 
construção de tal representação o surgimento de conhecimentos específicos e especializantes do homem sobre si mesmo. Não fugiu a isto o olhar e as formulações sobre as "perturbações físico-morais" do sujeito. O que constituía a loucura, a doença do corpo e/ou do espírito, estava sendo repensado por novos saberes e práticas, dentre os quais o aparecimento da psiquiatria, em separado da medicina geral, foi um exemplo. ${ }^{7}$

$\mathrm{Na}$ base desse movimento de idéias e teorias estavam os saberes científicos seiscentistas, que afirmavam que o modelo de explicação da física dos corpos devia ser separado das qualidades ocultas e dos elementos místicos que até então o tornavam decifrável. Em sua constituição, a medicina também buscava um status científico, adotando o novo modelo epistemológico do determinismo mecanicista. A construção de uma significação mecânica e material do corpo humano tornava possível postular que os sintomas das doenças eram provocados por causas específicas - os sintomas passavam a ser vistos como impressos no corpo humano e por intermédio do próprio corpo poder-se-ia chegar à causa que os desencadeara. Mas o dualismo cartesiano à época justificava a manutenção de explicações do corpo pelo corpo e do espírito pelo espírito, não possibilitando nenhuma relação de causalidade científica ou racional entre um corpo e um espírito. Do mesmo modo, o dualismo metafísico ou religioso não concebia que a doença do espírito, vista como pecado, estivesse relacionada a um prejuízo orgânico do pensamento. ${ }^{8}$

A constituição de uma inteligibilidade médica "moderna" se organizaria ainđa sobre a preponderância do espírito de observação, refletido no

MacPherson, A Teoria Politica do Individualismo Possessivo: De Hobbes a Locke. Rio de Janeiro, Paz e Terra, 1979; G. Simmel, On Individuality and Social Forms, Chicago, The University of Chicago Press, 1971.

7 Cabe ressaltar que a mudança da concepçào clássica da loucura para seu enquadramento pela emergência do saber psiquiátrico não foi imediata nem simples. A própria idéia de loucura na Idade Clássica já se diferenciava da concepçāo vigente na Idade Média, quando era vista como uma consciência dos poderes trágicos do mundo, representada nas ameaças da bestialidade e dos fins dos tempos, ou ainda uma desventura natural da Razão. O imaginário clássico sobre a loucura, por sua vez, a traria definitivamente para o campo da Razāo. encarnada em homens concretos, presentes no mundo social - o dissipador, o homossexual, o mágico e muitos outros. Essa foi a época do "grande internamento" da loucura nos asilos, embora ela ainda não houvesse sido separada em sua especificidade. Cf. M. Foucault, História da Loucura na Idade Clássica, São Paulo, Ed. Perspectiva, 1978.

8 Cf. G. Gusdorf. "L'Avènement de la Psychiatrie parmi les Sciences Humaines", Les Sciences de l'Homme Sont-Elles Sciences Humaines?, Paris, Faculté des Lettres de Strasbourg. 1967, pp. $157-82$. 
empirismo experimental da passagem do século XVII para o XVIII, assim como sobre o imenso prestígio da história natural, positiva e descritiva. fundada no Sistema Natural de Lineu. Pautada por esses modelos, a medicina "moderna" foi sendo construída a partir da preocupação com a classificação das doenças. "Isto significa a exigência de a doença ser compreendida como um fenômeno natural. Ela terá espécies, características observáveis, curso e desenvolvimento como toda planta". 9

Desta perspectiva, a medicina deixava de se ater às relações lógicas que se entendia conformadoras das enfermidades. Ela se afirmava deslocando. de modo crescente, a atenção das classificações ideais das doenças para a observação empírica das mesmas. Mais do que o fato de o homem ter passado a se observar, tratou-se de um tipo especial de observação que, por intermédio da atenção para com os fenômenos anátomo-patológicos, privilegiava as concepções fisicalistas a respeito do que se entendia por doença. Pelo estudo das patologias passava-se à busca da causa, orgânica, relacionada à lesão, que se acreditava provocar as doenças.

Paralelamente, entretanto, o pensamento vitalista do final do século XVIII defendia a assunção de uma lógica monista para a interpretação dos fenômenos da natureza, inclusive da natureza humana:

"Reduzido a sua expressão mais simples, o vitalismo é um monismo da vida que permite ao conhecimento do homem sair do impasse do dualismo cartesiano.[...]. O vitalismo é um monismo cujo ponto de aplicação situa-se na junção do espírito e do corpo, uma inteligência unitária que chama uma nova fenomenologia e uma nova interpretação dos signos, normais ou patológicos". 10

Desse modo, os distúrbios que afetavam o espírito humano passavam a ser considerados como obedecendo às mesmas leis que os que atingiam o corpo. O organismo, ponto de apreensão inicial de todo ser humano, passava a ser, ao mesmo tempo, o caminho pelo qual se captaria as qualidades morais dos indivíduos, seus vícios e virtudes. A redução naturalista e fisicalista do homem e de suas "perturbações" vinha, assim, a idealizá-lo como uma totalidade individualizada. ${ }^{11}$

9 M. Foucault, "O Nascimento do Hospital". in Microfisica do Poder (5 ${ }^{\mathrm{a}}$ ed.). Rio de Janeiro. Ed. Graal, 1985, p. 107.

10 G. Gusdorf. "L'Avènement...", op. cit., p. 173.

11 Conforme demonstra Luiz Fernando Duarte, durante o século XVIII afirmou-se um novo quadro de representações. relacionado de forma complexa com os saberes médicos-psicológicos da época, que demarcava os fenômenos físico-morais que se acreditava pudessem acometer o homem. O autor designa este quadro como a "configuração do nervoso". proviando que pela idéia de sistema nervoso se reordenou uma totalização individualizante do homem. Os nervos, 
Nesse contexto de saberes, na passagem do século XVIII para o XIX, surgia a psiquiatria. Seguramente, ela foi imbuída de um espírito filantrópico fundado pelo ideário iluminista e humanista do final do século XVIII, período marcado por uma radical mudança econômica, política e social, quando avultava a reformulação da assistência à miséria e à doença. Mas também é certo que todas as práticas sociais desse período estavam vinculadas de forma estreita ao modo como se forjavam os novos paradigmas de conhecimento e representação do homem pelo homem.

No interior do movimento de práticas e idéias emergentes dessa época, conformava-se a psiquiatria, marcadamente distanciada, no entanto, da medicina anátomo-patológica. Isto não quer dizer que não estavam sendo elaboradas teorias sobre a fundamentação orgânica das "perturbações físicomorais", mas somente que esse conhecimento anátomo-patológico foi subtraído à própria constituição da psiquiatria nascente, alienista. Se as primeiras classificações psiquiátricas filiavam-se ao naturalismo classificatório, levantando hipóteses a respeito do órgão onde a alienação mental poderia estar sediada, a importância e desenvolvimento dessas classificações se afirmou no sentido da procura das causalidades eminentemente morais da doença mental: deixava-se de privilegiar a atenção para com a "natureza" da alienação, passando-se a captar o que dessa natureza podia ser medido e compreendido.

Ser alienado mental significava ser um indivíduo de paixões excessivas, afetos intensos, que se sobrepunham à vontade. Esta última, por sua vez, era caracterizada como a instância em que se produzia o que era e o que não era permissível ao indivíduo, tendo em vista a atenção com sua dimensão social: "[...] ela [a vontade] seria a única entre as faculdades que seria simultaneamente individual e social". ${ }^{12}$

Com essa nova ordem explicativa, passava-se a considerar não somente as qualidades morais intrapessoais do indivíduo - o intelecto e os afetos -, mas também sua dimensão interpessoal que, garantida pela idéia de vontade, passava a ser relacionada de forma estreita com a própria dimensão intrapessoal do sujeito doente. Nesse sentido, paulatinamente, as teorizações a res-

observados enquanto expressão da fisicalidade do indivíduo, assumiram de modo crescente uma significação monista, traduzindo as "perturbações" como resultantes de uma combinação entre o organismo e os modos e efeitos do comportamento do indivíduo. Cf. L. F. Duarte, Da Vida Nervosa nas Classes Trabalhadoras Urbanas, Rio de Janeiro, Jorge Zahar Editor/CNPq, 1986.

12 J. Birman, A Psiquiatria como Discurso da Moralidade, Rio de Janeiro, Ed. Graal, 1978, p. 80 . 
peito da alienação mental incluíam ainda explicações sobre os malefícios que a sociedade trazia às duas qualidades intrapessoais do indivíduo: a função cerebral, intelectual, afetada pelo excesso de trabalho e os afetos intensos, as paixões, não controladas pela família. "O discurso não é mais o do corpo, mas o das relações entre as pessoas, mais precisamente das inter-relações no contexto familiar. O contexto moral é familiar e educacional". ${ }^{13}$

Em sua apreensão "moderna" da loucura, a psiquiatria trazia ainda como novidade a certeza na possibilidade da cura. Observava-se, com isso, a recusa a toda renúncia terapêutica a priori, entendendo-se que, na quase totalidade dos casos, o tratamento dos alienados podia ter êxito, mesmo entre os até então incuráveis. Possibilidade intrínseca à psiquiatria alienista essa da cura, porque ao se afirmar que o indivíduo estava alienado, entendia-se também, e antes disso, que ele era da mesma natureza que os outros indivíduos e, portanto, potencialmente apreensível por estes. ${ }^{14}$ Ser alienado significava assim ser ao mesmo tempo um igual e um diferente de seus pares: igual em sua natureza e diferente também por esta natureza que lhe permitia externar sua alteridade individual, intrapessoal.

Para essa possibilidade que passava a ser colocada, indicou-se o tratamento moral, balizado por um novo tipo de instituição, a saber, o asilo. $\mathrm{O}$ primeiro consistia na aplicação de métodos pautados na crença na igualdade dos seres, que vinha se sobrepor à diferença individual dada por uma liberdade alienante. Métodos que visavam ao aplacamento das paixões e à reconstituição da vontade: a certeza na possibilidade de comunicação entre o alienista e o alienado e nos poderes do discurso do primeiro para penetrar na alienação do segundo a fim de restituí-lo em sua vontade ${ }^{15}$ Desse modo, a psiquiatria alienista minimizava a especificidade da concepção de loucura até então vigente, já que a reduzia somente a uma exacerbação ou incongruência de qualidades (as paixões e a vontade) vistas como indiscriminadamente comuns a todos os seres humanos.

$\mathrm{O}$ asilo voltava a afirmar sua necessidade enquanto instituição de assistência, como ocorrera no século XVII. Mas não era mais uma instituição definida pela exclusão, ainda que acompanhada pela atenção médica. A instituição asilar passava a reunir esses dois aspectos em um só, prescrevendo a pertinência do isolamento terapêutico. Este se justificava como primeira

13 Ibidem.

14 Cf. M. Gauchet e G. Swain, La Pratique de l'Esprit Humain: l'Instituition Asilaire et la Révolution Démocratique, Paris, Gallimard, 1980.

15 Idem. 
etapa terapêutica porque, estando afastado da sociedade. o alienado não seria mais impulsionado pelas ocorrências cotidianas, pela forma de estruturação das inter-relações sociais e pelos sentimentos daí advindos que reificavam as paixões e a incongruência da vontade. A nova instituição vinha, assim, a ser a tentativa prática de realizar a produção de uma ordem pautada pelos princípios do tratamento moral, ampliando-os do plano individual para o coletivo: a formação de um colețivo do qual os alienados seriam parte integrante. Retirava-se os alienados do convívio social, mas para lhes proporcionar a convivência em uma microssociedade organizada para transformar os afetos intensos e incentivar a vontade, sob os auspícios de uma vontade coletiva, imaginada mais imperiosa que a individual, alienada ${ }^{16} \mathrm{~A}$ instituição asilar, dirigida pelo médico-psiquiatra e seu poder de atuar na dimensão intrapessoal do indivíduo, passaria também a ter a capacidade de restabelecer a dimensão interpessoal do alienado. Com isto provaria que o alienado era passível de ser "alcançado" e de fazer parte de um coletivo, ainda que especial e fechado, tornando-o um "indivíduo-no-mundo". Ancorada nessas teorias sobre a alienação mental enquanto fenômeno moral, a psiquiatria nascente demonstrava fazer parte do processo global de construção da Pessoa moderna individualizada.

\section{Psiquiatria e "Nova Psiquiatria"}

A psiquiatria e sua concepção a respeito das "perturbações físico-morais" até então chamadas de loucura caracterizou-se pelo estabelecimento de relações estreitas entre assistência, instituição e cura. É certo que a questão da assistência a ser prestada pelo Estado aos indivíduos considerados insensatos já estava presente há muito tempo, assim como os projetos em torno das instituições próprias para tal tarefa. Mas foi com a psiquiatria, a partir de Pinel, quando se colocou de modo irrevogável a enunciação da possibilidade da cura, que a preocupação com a assistência e a instituição para

16 Idem. Cumpre destacar que estes autores estão discutindo com Foucault: ao trazerem a idéia de que o ideal do asilo era o de integrar o sujeito no mundo. contrapōem-se à idéia foucaultiana de que o asilo era o lugar da segregação. dada a oposição radical e mais geral que o ideário moderno estabeleceu entre Razāo e Desrazão. No meu entender. embora priorizando enfoques diterentes. as duas explicações sobre o asilo não são excludentes. Idealizado para integrar os alienados no mundo, o asilo certamente passou a ser também expressão do espaço para a exclusão que estava sendo socialmente reconstruído. Neste sentido. os alienados passavam a ser incorporados como figuras sociais ao mundo, exatamente em suas margens. 
tratamento ganharam novo sentido, ajudando à construção do novo saber e da prática específica para lidar com o que se passava a chamar de alienação mental.

A eficácia terapêutica pretendida pelos alienistas não foi, porém, atingida - não apenas nos termos em que hoje poderíamos julgá-la, mas, inclusive, pelos padrões e critérios da época. Entretanto, isso não nos autoriza a eliminar as diferenças de significados a respeito do que se entendia, antes e depois de Pinel, por tratamento. Para além da questão da eficácia, cabe observar que o ato de tratar passou a ter, ele mesmo, uma nova significação e a ineficiência pineliana apontou à psiquiatria uma outra ordem de problemas, exigindo mais e mais tentativas para a compreensão e apreensão de seu objeto

O que a ineficácia prática da primeira psiquiatria trouxe à experiência dos alienistas foi a revelação de um aspecto suplementar da alienação, relativo à sua perpetuação no tempo, o que se passou a chamar de cronicidade: uma incurabilidade de fato, mas que não tinha nada a ver com aquela que descartava a priori o tratamento. Não se tratava mais do caráter inacessível da alienação, da impossibilidade de sua comunicação, mas de uma espécie de suspensão da duração do tempo, que se tornava indefinido. A renúncia ao par incurabilidade-curabilidade pela prevalência do segundo termo juntou-se à inserção da idéia de loucura na dimensão temporal, enquanto dimensão determinante para a validade de qualquer terapêutica. E a cronicidade era expressão, exatamente, da maneira específica da alienação perdurar no tempo em confronto com a idéia a priori da curabilidade. ${ }^{17}$

É certo que as próprias representações psiquiátricas a respeito da cronicidade não foram unívocas. A partir da nosografia de Kraepelin sobre a demência precoce em meados do século XIX, a cronicidade tem sido considerada por muitos como inerente a alguns casos de doença mental, enquanto para o ideário da "nova psiquiatria", como se verá, a chamada cronicidade seria advinda do mau uso de métodos ditos terapêuticos, como o isolamento asilar. Entretanto, devemos considerar que essas representações servem como argumentos a posteriori para dar conta da crença primeira na possibilidade da cura da doença mental, enquanto fenômeno que perdura no tempo.

De qualquer modo, a produção desse aspecto suplementar da alienação, que se passou a chamar de cronicidade, não veio a ser o fim da psiquiatria, mas seu verdadeiro início. A constatação da "ineficácia" terapêutica da 
psiquiatria alienista, eminentemente moral, favoreceu, a partir da segunda metade do século XIX, a difusão e a exacerbação das explicações propriamente físicas acerca da doença mental. As muitas descobertas biomédicas neste período levaram a que os sintomas neurológicos fossem agrupados em "síndromes" e "doenças", as lesões crescentemente investigadas em termos de suas localizações para a explicação dos fenômenos clínicos, e a "doença mental" compreendida a partir desses dois referenciais. O conhecimento psiquiátrico passou a desenvolver intensamente sua clínica e a se valer das descobertas no campo da neurofisiologia (que já dava origem à neurologia) para apresentar sistematizações da "doença mental" sob uma ótica preponderantemente fisicalista. ${ }^{18}$

Cabe ressaltar, porém, que a prevalência da representação fisicalista, organicista, da doença mental não invalidou a ocorrência de explicações pela ordem moral dos indivíduos, já então crescentemente vista como psicológi$c a$. Essas duas linhas de força - a física e a moral - estiveram em tensão durante toda a primeira metade do século XX. Por um lado, as explicações fisicalistas, marcadamente neurológicas, levavam a um tipo de observação que fragmentava o indivíduo em suas partes físicas mais internas. Assim, o enfoque físico, específico e especializante, não se propôs, concomitantemente, a tentar compreender a dimensão moral. Esta, por outro lado, interpretada pelas teorias da psicologia experimental presentes desde a segunda metade do século XIX e pelo "advento" do conhecimento psicanalítico freudiano, era definida de forma também cada vez mais referida à interioridade individual, mas uma interioridade não-física, apreendida, fundamentalmente, com base nas idéias acerca do inconsciente. ${ }^{19}$

Em termos da assistência à doença mental foi a instituição asilar que permaneceu. Uma instituição assistencial que não era mais vista como um unívoco bastião de cura para o conhecimento psiquiátrico, mas que aglutinava pragmaticamente em seu interior as várias terapêuticas criadas desde

18 Dentre as diversas descrições e classificações realizadas nessa segunda metade do século XIX. a de Kraepelin pode ser considerada paradigmática: o Compêndio de Psiquiatria, publicado pela primeira vez em 1883, teve nove edições amplamente aumentadas até 1927.

19 Enquanto linhas de força, os enfoques físico e moral certamente não foram tão estanques como aqui exposto. As próprias experiências de Freud continham em sua base a tensão físico-moral. Entretanto, nos limites deste artigo não será possível aprofundar o modo complexo como essas duas dimensões coexistiram, ressaltando-se somente sua presença simultânea na constituição da psiquiatria, como demonstra, por exemplo, a análise de Luiz Fernando Duarte sobre as proposições de Krafft-Ebing. L. F. Duarte, "A Psychopathia Sexualis de Krafft-Ebing, ou o Progresso Moral pela Ciência das Perversões", Jornal Brasileiro de Psiquiatria, vol. 38, nos 2 e 3, 1989. 
meados do século XIX até a primeira metade do século XX. Durante este último período, os tratamentos prescritos refletiam a prevalência da atenção física ao indivíduo doente: dentre eles, a lobotomia, a eletroconvulsoterapia, a malarioterapia (que deu a Julius von Wagner-Jauregg o Prêmio Nobel de 1927) e as crescentes pesquisas na área da psicofarmacoterapia que, a partir dos anos 50, possibilitaram a utilização dos psicofármacos. Também ao longo da primeira metade do século XX observou-se o aprofundamento e a difusão da psicanálise freudiana no trato com os problemas psicopatológicos, mas nesse período a psicanálise não foi utilizada como recurso terapêutico nas instituições psiquiátricas públicas. ${ }^{20} \mathrm{~A}$ assistência psiquiátrica seguia claramente os rumos do fisicalismo.

No entanto, no contexto de "reliberalização" do pós-Segunda Guerra Mundial, a psiquiatria ressurgiu enquanto "nova psiquiatria". Um período de reconstrução social pautado tanto pela "dúvida" sobre os novos caminhos a serem trilhados, quanto pela "experimentação" de alternativas que correspondessem às expectativas sociais de igualdade e liberdade. A vitória dos aliados contra o nazi-fascismo consolidava o repúdio à repressão e ao totalitarismo. Tratava-se de planejar uma organização do Estado e de suas políticas assistenciais que dessem conta da "liberdade" e da "igualdade social" no interior das sociedades capitalistas devastadas pela guerra, mas vencedoras.

Imbuído desse ideário igualitário-libertário, o campo psiquiátrico, na Europa e nos Estados Unidos, dava origem a uma série de novas "experiências": as comunidades terapêticas e a Antipsiquiatria, na Inglaterra; a Psicoterapia Institucional e a Psiquiatria de Setor, na França; a Psiquiatria Comunitária ou Preventiva, nos Estados Unidos; e, no final da década de 1960, a Psiquiatria Democrática, na Itália. Experiências que se opunham à prevalência da atenção à fisicalidade da doença mental e, principalmente, ao isolamento terapêutico, reivindicando a necessidade da desinstitucionalização.

O ideário da "nova psiquiatria" se constituiu, fundamentalmente, a partir do a priori de que o indivíduo doente devia se manter estritamente vinculado à sociedade. Afirmava-se primordial reverter a situação de exclu-

20 É interessante, porém, verificar que já à época da Primeira Guerra Mundial, dois médicos ingleses, que depois se tornaram eminentes antropólogos (Rivers e Seligman), se interessaram pelas possibilidades terapêuticas da psicanálise ao lidarem com neuroses traumáticas de guerra. Cf. L. F. Duarte, "Freud e a Imaginação Sociológica Moderna”, in J. Birman, ed., Freud 50 Anos Depois, Rio de Janeiro. Ed. Relume-Dumará, 1989. 
são đo doente mental, considerada decorrente da própria sociedade — ou da concepção social acerca da doença mental - que o internou e isolou por tanto tempo, tornando-o cada vez mais doente, crônico. Como princípio fundamental preconizou-se a prestação de uma assistência fornecida pelo Estado que procurasse garantir um contato contínuo do indivíduo doente com a sociedade. Esta, por sua vez, para esses segmentos críticos, passava a ser representada paradigmaticamente pela idéia de uma nova comunidade, isto é, um grupo de indivíduos que se autocaracterizavam como "comuns", porque iguais entre si; mas ao mesmo tempo, contrariamente à linha mestra da ideologia moderna, congregados por um forte sentimento de fraternidade. ${ }^{21}$

Esse novo imaginário psiquiátrico trazia de volta o ideal da igualdade entre os indivíduos. Ao mesmo tempo, entretanto, propunha-se a reformular os espaços para a "diferença" da qual a chamada doença mental era expressão. Nesse sentido, na raiz da "nova psiquiatria" mantinha-se a questão da relação entre a assistência à doença mental e a instituição ideal, pertinente à tarefa de tratar e que levasse, em última instância, à concretização da cura. Foram criadas, assim, uma série de instituições assistenciais para intermediar o processo de reinserção social do doente mental: hospitais-dia, centros de atenção, centros de saúde comunitária etc. ${ }^{22} \mathrm{O}$ objetivo era tratar $\mathrm{o}$

21 O uso moderno da categoria de comunidade é um corolário complexo do ideário individualista. Segundo Viveiros de Castro e Benzaquen de Araújo, as consideraçōes de Turner sobre a oposição communitas/estrutura pode ser comparada à distinção de Dumont entre universitas e societas. Cf. E. Viveiros de Castro e R. Benzaquen de Araújo, "Romeu e Julieta e a Origem do Estado", in G. Velho, org.. Arte e Sociedade, Rio de Janeiro, Zahar, 1977, pp. 130-69; V. Turner, O Processo Ritual, Petrópolis, Vozes, 1974; L. Dumont, "The Modern Conception....", $o p$. cit. De acordo com a análise dos autores brasileiros, Turner privilegia uma distinção sincrônica entre communitas e estrutura, afirmando que a primeira "dissolve a estrutura para pôr em relevo indivíduos, não como seres moralmente autônomos (que comporiam a societas), e sim como membros de uma humanidade indiferenciada, quase-física. Por outro lado, Turner vai aproximar-se de Dumont ao mostrar, recentemente, como a liminaridade da communitas é tendência que. de domesticada nas sociedades tradicionais. passa a definir certa concepção dominante de mundo na sociedade moderna, contaminando todo um conjunto de atividades e valores". Cf. E. Viveiros de Castro e R. Benzaquen de Araújo, "Romeu e Julieta...", op. cit., p. 135, nota 7. A referência a Turner diz respeito a V. Turner. Liminality, Play, Flow and Ritual: Optional and Obligatory Forms and Genres, s/l. Wenner-Green Foundation for Anthropological Research, 1974, mimeo.

22 Entre as poucas referências brasileiras descritivas do panorama internacional da "nova psiquiatria", uma explicação detalhada a esse respeito, assim como sobre os modelos institucionais então criados, pode ser encontrada em A. M. Pitta-Hoisel, A.M. Sobre uma Política de Saúde Mental, Tese de Mestrado, Departamento de Medicina Preventiva/Faculdade de Medicina/USP, 1984. 
indivíduo sem interná-lo, fazendo-o retornar ao convívio familiar após um período diurno de tratamento.

No entanto, na base de todas essas tentativas de se achar a instituição que desse conta da tarefa de assistir a doença mental, era o asilo que ressurgia, pela constatação de que, de forma sutil e arraigada, era a "ordem asilar" que ainda persistia nos novos modelos institucionais. Chegou-se a "desospitalizar" o doente mental, mas não a "desinstitucionalizá-lo". E a "desospitalização" não o levou para uma "comunidade", não implicou sua aceitação enquanto um igual, desviou-o apenas em seu trajeto para outras instituições ainda especiais para ele.

Somente com a Psiquiatria Democrática italiana é que a questão da desinstitucionalização foi retomada, para reafirmar em toda a sua radicalidade a oposição à instituição asilar: instituição representativa das relações de poder perversas e nocivas que não permitiriam ao homem a garantia de sua igualdade nem a expressão de sua liberdade. Em oposição à exterioridade do poder médico sobre a "comunidade" de internos do asilo, propunha-se um poder idealizado como contribuição ativa, permanente e geral dos indivíduos com relação a si mesmos e à comunidade que formavam, um poder que em sua expressão limite estava representado na noção de autogestão.

A partir dessa premissa a Psiquiatria Democrática defenderia novamente a idéia inglesa de comunidade terapêutica - mas considerando que a terapêutica só seria eficaz se levasse às últimas conseqüências a questão do poder "igualitário" que deveria permear a comunidade. O princípio da inserção social também foi retomado com a proposta de estabelecimento de um contato estreito do indivíduo doente com a população local, ou sua não-separação de seu círculo relacional, porém utilizando o que se entendia ser uma nova proposta, percorrendo o caminho inverso das experiências anteriores: abrir o asilo para trazer a população local para vê-lo e transformá-lo por dentro, em vez de procurar somente levar os doentes para fora da instituição. ${ }^{23}$ Assim, toda a "comunidade local" seria especial com relação ao que tinha sido até então, porque se incorporava àqueles que rejeitara há quase dois séculos, reconhecendo que o doente mental era, em um determinado nível, um.igual, um ser social, embora trouxesse a marca da alteridade.

Com isto a "nova psiquiatria" trazia de volta a perspectiva que deu origem à psiquiatria, inovadora na esperança da cura. Porque se no início do

23 Sobre a Psiquiatria Democrática italiana, ver F. Basaglia, A Psiquiatria Alternativa: Contra o Pessimismo da Razão, o Otimismo da Prática, São Paulo, Ed. Brasil Debates, 1979; F. Basaglia, A Instituição Negada, Rio de Janeiro, Ed. Graal, 1985. 
século XIX se considerava que o doente mental era um alienado de outros e de si próprio, por outro lado, entendia-se que ele era um igual e, por isso, possivelmente apreensível por um "outro".

Também a exemplo da psiquiatria alienista que, com Pinel, desacorrentara os loucos, a "nova psiquiatria" trouxe de volta o ideal libertário que favorecia a tentativa de entendimento da dimensão moral do indivíduo doente. Juntamente com a crítica à perpetuação do asilo, a "nova psiquiatria" se opunha à psiquiatria organicista, pautada por tratamentos que incidiam somente sobre o âmbito físico, orgânico do indivíduo: desde a eletroconvulsoterapia ou eletrochoque até o uso considerado abusivo de psicofármacos. Para as "novas" propostas do campo psiquiátrico, o "organicismo" ou "mecanicismo" de métodos considerados violentos e autoritários eram cerceadores da "liberdade" do indíviduo.

Nesse sentido, a "nova psiquiatria" retomou a tentativa de compreender os mecanismos individuais referenciados, cada vez mais, na esfera $p s i$ cológica, agora subjetiva, do homem. Para tal passou a elaborar um conhecimento e uma prática que procuravam relacionar as dimensões interpessoal e intrapessoal do indivíduo, subjugando o interpessoal ao intrapessoal. Embora a "nova psiquiatria" discursasse sobre a questão "social", sobre a exclusão social ou os preconceitos da sociedade em relação à doença mental, ao mesmo tempo restringia a representação do social ao comunitário, coletivo (no sentido da preeminência lógica do individual). Assim, na experiência inglesa das comunidades terapêuticas os tratamentos sugeridos deveriam ser grupais e de algum modo psicoterápicos, procurando-se tratar grupos de pacientes como se fossem um único organismo psicológico. Já a experiência francesa da Psicoterapia Institucional se utilizaria, principalmente, da psicanálise para tratar o coletivo que a instituição representava. ${ }^{24}$ Com essas propostas, confirmava-se o fundamento a priori de que o indivíduo doente deveria estar estreitamente relacionado à sociedade enquanto coletividade, na medida em que ele era considerado como uma pessoa individualizada, ou seja, constituído de uma dimensão interpessoal, mas que era representada enquanto tal pelo contraste com a existência de uma dimensão intrapessoal, lugar da singularidade individual.

24 Sobre as concepções fundamentadoras da experiência inglesa, ver M. Jones, La Psiquiatria Social en la Práctica: La Idea de la Comunidad Terapéutica, Buenos Aires, Editorial Americale, 1970. No que se refere à experiência francesa, ver J. Oury, Psychiatrie et Psychothérapie Institutionelle, Paris, Payot, 1977; D. Roulot, Apresentação oral no I Encontro sobre Tratamento das Psicoses, São Paulo, Associação Franco Basaglia, 1989, mimeo. 
A Psiquiatria Democrática italiana também não fugiu a essas proposições. Atualizou-as de modo diferencial, é verdade, mas para recolocar de modo mais explícito as questões que estavam em pauta. Ela recusou as propostas da Psicoterapia Institucional francesa porque acreditava que a questão da instituição não precisava ser tratada, mas eliminada. Como se viu, a inserção do indivíduo na sociedade seguiu outras estratégias. Estas não inviabilizavam, no entanto, a alternativa das comunidades terapêuticas, a conseqüente aceitação de que o social fosse traduzido como coletivo e, esse, visualizado por parâmetros fundamentadores de uma análise do indivíduo, a saber: a consideração de que existiriam razões de ordem interna, intrínsecas ao próprio coletivo, que elucidavam seu modo de ser e que, se entendidas, poderiam ser modificadas. Assim, se aperfeiçoaria o próprio coletivo segundo o ideal almejado.

Tudo isso, entretanto, só fazia sentido porque se tratava de tentar compreender os indivíduos até então considerados "doentes mentais", isto é, possuidores de uma alteridade que os limitava enquanto tais. Para a experiência italiana, expressiva da "nova psiquiatria", essa alteridade significava uma subjetividade acoplada a um sofrimento interior. Significava muito, portanto. Mediante essas noções, privilegiava-se novamente a idéia de que o indivíduo possuía uma dimensão intrapessoal - sua subjetividade - que deveria ser compreendida. A possibilidade de sua compreensão, por sua vez, estava implicada pela concepção de que não só o doente mental, mas todos os indivíduos possuem uma dimensão subjetiva, sendo, portanto, possivelmente, comunicantes entre si.

Essa idéia, que pode ser considerada óbvia ou verdadeira para muitos, deve, no entanto, ser entendida em toda a sua complexidade por atualizar de modo radical o imaginário "moderno" do homem sobre si mesmo. Divergente do imaginário não-moderno, em que os sujeitos são vistos como diferentes enquanto partes de conjuntos sociais, o ideário "moderno" os considera como livres e iguais, sem determinação social ou transcendente, possibilitando que sejam convertidos em objetos de investigação e prática sociais.

Pela consideração do que denominou de subjetividade, a "nova psiquiatria" reinvocava a possibilidade de compreensão do doente mental, reinscrevendo toda a positividade do valor-Indivíduo. Em um primeiro nível, não se tratava mais de um doente, mas de um sujeito que devia ser observado pela sua capacidade de ser saudável, pela sua saúde mental. A idéia de saúde mental abria ao chamado doente mental a possibilidade de ter um mesmo estatuto que os outros indivíduos, isto é, o de se afirmar por uma objetividade, que é a de sua própria subjetividade. Em um segundo nível, a assunção 
da idéia de que essa subjetividade se expressava fundamentalmente por meio de um sofrimento: sofrimento este não definido inteiramente, justificado algumas vezes pelas chamadas "condições objetivas" de vida, mas que, em última instância, era remetido sempre à construção intrapessoal do indivíduo assim representado paradigmaticamente enquanto sujeito.

A partir desta análise, pode-se pensar sobre as dificuldades enfrentadas pela "nova psiquiatria" para levar adiante, e com êxito, sua tentativa de apreensão da questão da doença mental. Não estou querendo argumentar com isso a respeito de uma "ineficácia" particular da "nova psiquiatria", mas apontar que também nesse caso permanecem as problemáticas suscitadas quando do aparecimento da psiquiatria e que a acompanham há tanto tempo. O que sobressai do contexto atual, entretanto, é que tal permanência se apresenta de uma "nova" forma, de modo ainda a produzir desdobramentos para a psiquiatria como um todo: seja, negativamente, por meio das questões que a "nova psiquiatria" deixa em aberto (particularmente no estímulo ao crescimento de uma psiquiatria dita biologizante), seja mediante os deslocamentos que traz para a a psiquiatria como um todo, dentre os quais se incluem as novas possibilidades de representação do sujeito.

$\mathrm{Na}$ base da conformação do ideário da "nova psiquiatria" encontra-se a recusa a uma série de métodos "tradicionais", que são vistos como representantes de uma exclusiva atenção à dimensão orgânica do paciente, criticada como "individualizante" pela concomitância que, historicamente, vem tendo com a "segregação social", esta última também designada como característica de tais métodos. A instituição asilar seria a expressão mais paradigmática dessas críticas, desdobrada tanto no isolamento social a que teria submetido os doente mentais, quanto nos recursos utilizados em seu interior. O eletrochoque, a internação prolongada e o suposto uso abusivo dos psicofármacos, são considerados recursos fundamentadores de uma psiquiatria biológica, à qual a "nova psiquiatria" se contrapõe.

Por oposição a tudo isso o novo ideário privilegia a atenção à dimensão social do doente mental e à sua esfera individual, só que em vez de orgânica, psicológica. Com isso, a "nova psiquiatria" passa a engendrar uma série de saberes e práticas específicas que pretendem substituir a idéia de doença mental, mantida por quase dois séculos, pela de saúde mental.

A atenção à dimensão social enfatiza a necessidade de efetivação de valores políticos "democráticos" que, promovendo a abertura para o social, tomam forma via o ideário "comunitário". A noção fundamental e balizado- 
ra da "nova psiquiatria", de considerar o doente mental como necessariamente vinculado à sociedade em que vive, traz consigo a idéia de comunidade: seja quando da referência ao nível mais abrangente da sociedade como um todo, seja quando da conformação das "novas" unidades assistenciais que, em última instância, se apóiam no ideal de "comunidade terapêutica". Uma noção - essa de comunidade - que serve para representar, nos mais diferentes níveis, o imaginário de que todos os indivíduos são iguais, idênticos entre si, e além disto pretensamente solidários e integrados (diferęntemente do fio central da ideologia moderna que os representa como independentes e autônomos).

Da dimensão individual da "nova" etiologia emerge um crescente interesse pela dimensão psicológica dos acometidos pela doença mental. Essa dimensão é apreendida a partir de um leque de abordagens que vai desde a aplicabilidade do saber "psicanalítico", até a enunciação de práticas terapêuticas que poderiam ser consideradas "pós-psicologizantes", na medida em que denotam, juntamente com a ênfase na dimensão dita psicológica do indivíduo, uma preocupação com a qualidade "humana" deste, entendendo essa qualidade como expressão e comprovação da existência de uma totalidade "cósmica". Com isso a "nova psiquiatria" exacerba as possibilidades de o indivíduo doente passar a ser tratado mediante o seu potencial único, a sua "liberdade em ser". Liberdade esta remetida à dimensão psicológica que vem conformar a "nova psiquiatria" como um retorno da tendência que subsume o âmbito físico ao moral.

Com a construção dessa etiologia e desse olhar ao mesmo tempo social e individual a respeito da doença mental a "nova psiquiatria" acaba reinvocando os valores de igualdade e liberdade, característicos das chamadas sociedades modernas, e revalidando concepções acerca da Pessoa individualizada. Uma reinvocação, entretanto, que traz consigo os paradoxos da consideração concomitante desses dois valores, pois se é certo que na base da configuração ideológica "moderna" são os valores da igualdade e da liberdade que têm estado presentes, a sua coexistência não tem sido simplesmente complementar. Ao contrário, o que se verifica por intermédio da ideologia da "nova psiquiatria" é que a ênfase simultânea nesses dois valores suscita uma série de questões que ainda estão por ser respondidas. Questões relativas às possibilidades de apreensão da realidade da doença mental, proporcionando, ao mesmo tempo, que o sujeito tenha garantidos os valores da igualdade e da liberdade. Por essa via é novamente a ilusão necessária do imaginário "moderno" que ressurge, ao encerrar em si a marca de uma configuração de valores que, se não ocupa a totalidade social moderna, não cessa, porém, de 
produzir novas roupagens para exprimir seu anseio de totalização pela liberdade e pela igualdade.

\section{RESUMO}

\section{A Construção Social da Pessoa e a Psiquiatria:} Do Alienismo à "Nova Psiquiatria"

O artigo trata das representações da psiquiatria a respeito da noção de Pessoa, procurando demonstrar, em particular, de que forma tais representações são expressão do valor Indivíduo e dos corolários da igualdade e da liberdade. Focaliza-se, neste sentido, o surgimento da primeira psiquiatria, alienista, e a reordenação, a partir da Segunda Guerra Mundial, de um novo conjunto de saberes e práticas terapêuticas aqui denominado de "nova psiquiatria". A partir de um estudo comparativo, argumenta-se sobre a tensão físico-moral constitutiva da construção social da Pessoa moderna em suas diferentes formas de atualização, e analisa-se as rupturas e continuidades entre as idéias que fundamentam a psiquiatria alienista e a "nova psiquiatria".

\section{ABSTRACT \\ The Social Construction of Self and Psychiatry: From Alienism to the "New Psychiatry"}

In addressing psychiatry's representations of the notion of self, the article endeavors especially to show in what way these representations are an expression of the value individual and of the corollaries equality and freedom. In doing so, it focuses on the emergence of the first psychiatry [alienist] and on a reorganizing, as of World War II, of therapeutic knowledge and practices, herein designated the new psychiatry. Drawing from a comparative study, the article discusses the physical-moral tension constituent in the social construction of the modern self in its different forms of actualization and analyzes the breaks and continuities between the ideas underpinning alienist psychiatry and the new psychiatry. 


\section{RESUME \\ La Construction Sociale de la Personne et la Psychiatrie: de l'Aliénisme à la "Nouvelle Psychiatrie"}

Cet article traite des représentations de la notion de Personne propres à la psychiatrie. Il tente notamment de démontrer qu'elles sont l'expression de la valeur individu et des corollaires de l'égalité et de la liberté. C'esṫ pourquoi il met en évidence les premiers moments de la psychiatrie, en d'autres mots l'époque de l'aliénisme, et l'établissement, à partir de la Seconde Guerre Mondiale, d'un nouvel ensemble de savoirs et de pratiques thérapeutiques qui prendront ici le nom de "nouvelle psychiatrie". A partir d'une étude comparative, l'auteur développe une argumentation sur la tension physico-morale constitutive de la construction sociale de la Personne moderne à travers ses différentes formes d'action. Il analyse en outre les ruptures et les continuités qui se sont manifestées au sein des idées fonodamentales de la psychiatrie et de la "nouvelle psychiatrie". 
